\title{
Ring 20 chromosome phenotype
}

\author{
B PORFIRIO, M G VALORANI, A GIANNOTTI*, G SABETTA*, \\ AND B DALLAPICCOLA \\ Cattedra di Genetica, Dipartimento di Sanità Pubblica, II Università di Roma; and *Ospedale Bambino \\ Gesù, Istituto di Ricerca Scientifica, Rome, Italy.
}

SUMmary A baby with a $46, \mathrm{XY}, \mathrm{r}(20)$ karyotype is described. The distinguishing features of this rare chromosome anomaly are analysed in the light of the suggested $r(20)$ syndrome.

The existence of a ring 20 chromosome syndrome, characterised by neurological impairment, low IQ. and behavioural and psychological problems from infancy or childhood. was suggested in 1976 by Borgaonkar et al. ${ }^{1}$ on the basis of similarities in the phenotype of three reported patients. ${ }^{2-4}$ This has been corroborated by a small number of subsequent reports which have confirmed that these subjects have several features in common. In 1979. Stewart et $a l^{5}$ re-examined six cases and concluded that all had seizures and three had behavioural problems of various types. Intelligence quotients ranged from 18 to 80 . None had visceral malformations and physical anomalies were negligible.

We report an additional observation of $r(20)$ found in a patient without seizures and with a complex congenital heart defect.

\section{Case report}

This boy, the only child of healthy, unrelated parents, was born in 1983, when the father was 28 and the mother 22 years old. Delivery was spontaneous, normal, and at term following an uncomplicated pregnancy. Birth weight was $3600 \mathrm{~g}$ and head circumference $33.5 \mathrm{~cm}$. A congenital heart defect was recognised at 18 days of age. Echocardiography showed an ostium secundum type atrial defect. He smiled at seven weeks and sat unsupported at seven months.

When examined by us at 15 months, he was unable to stand unsupported and had no speech. His weight was $8.2 \mathrm{~kg}$ and his height $73 \mathrm{~cm}$, both well below the 3 rd centile. The facial appearance was not strikingly unusual (fig 1). There was no abnormality in the shape or size of the skull, but the fontanelles were still widely open. The forehead was high arched, with a flat glabella, rounded nasal tip, long philtrum, low set and prominent ears, and mild

Reccived for publication 27 Fibruary 1986.

Revised version accepted for publication 23 April 1986.

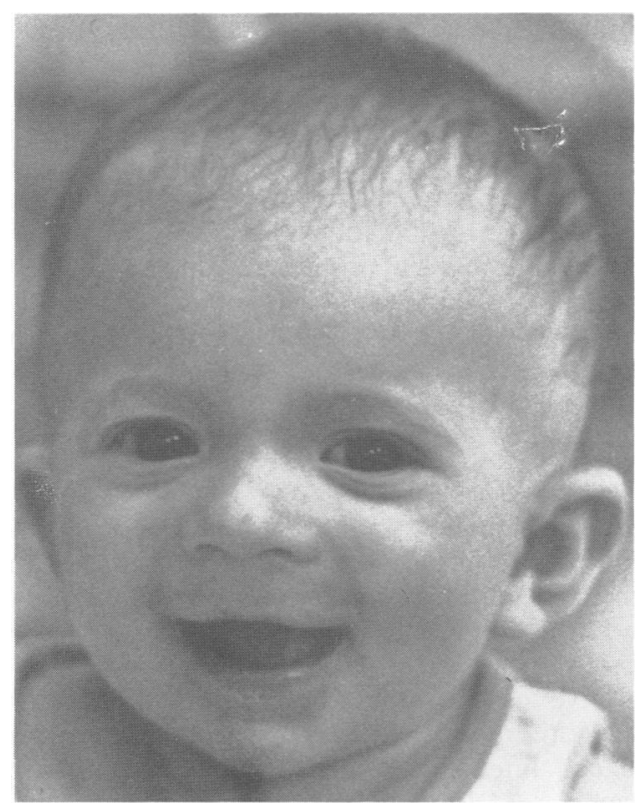

FIG 1 Facial appearance of the patient.

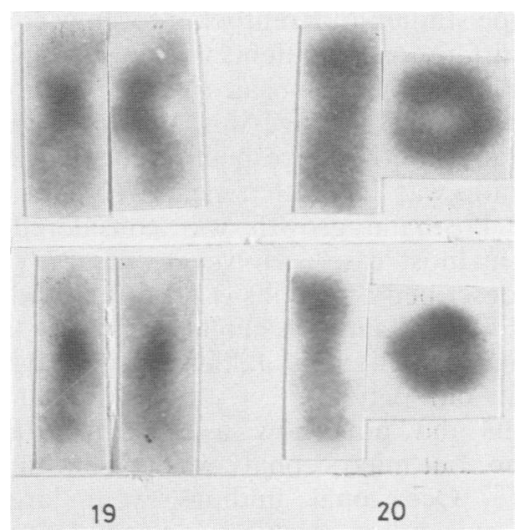

FIG 2 Partial karyotype of $F$ group chromosomes from two selected cells. 
micrognathia. Ocular examination showed bilateral strabismus. The testes were palpable in the inguinal canals. There was bilateral talipes. Neurological examination was normal except for mild hypotonia. Mental development was considered mildly retarded. Dermatoglyphic analysis was unremarkable. Electroencephalogram, CT scan, and complete skeletal radiological survey were normal. Routine haematological studies, including amino acids and immunoglobulins, were also normal.

\section{CYTOGENETIC STUDIES}

Chromosome analysis was carried out on lymphocyte cultures on two occasions. In total, $120 \mathrm{GAG}$ banded metaphases were analysed and showed a $46, X Y, r(20)(p 13 q 13)$ karyotype (fig 2). The ring structure was present in all cells and there was no evidence of mosaicism. No other tissues were available for cytogenetic studies. Parental chromosomes were normal.

\section{Discussion}

Eight other patients with a ring 20 chromosome have been reported (table), one of whom has not been confirmed by banding studies." However, this case has been included in our discussion because of the similarities to our own patient.

In five $\operatorname{cases}^{3-7}$ the abnormality arose from a postzygotic mutation, as shown by the coexistence of a cell line with a normal karyotype. In three instances,,$^{379}$ loss, pulverisation, enlargement, or duplication of the ring was recorded, indicating instability, which is common in rings, but in most cases these rings were fairly stable. It has been suggested that this could be the explanation for the definite clinical picture." However, karyotypephenotype studies apparently fail to show consistent clinical differences in patients with unstable vs stable or with non-mosaic vs mosaic ring 20 chromosomes.

The mean parental age was 31 and 28 years for fathers and mothers, respectively. The male to female ratio was $2: 1$, with a mean weight at birth of 3245 g. Postnatal growth was considered to be normal in most cases. However, the 27 year old patient described by Jacobs et al was considered to be small for age, and the height was below the 10th centile in the patient of Jalbert $e \mathrm{al}^{7}$ and the 3rd centile in our patient.

Patients did not show a distinct dysmorphic syndrome, but microcephaly was present in four of them. ${ }^{27-4}$ Occasional findings were large fontanelles, epicanthus, strabismus, prominent or large nose, prominent ears, micrognathia, low total ridge count (TRC) on the fingertips, short fifth fingers,

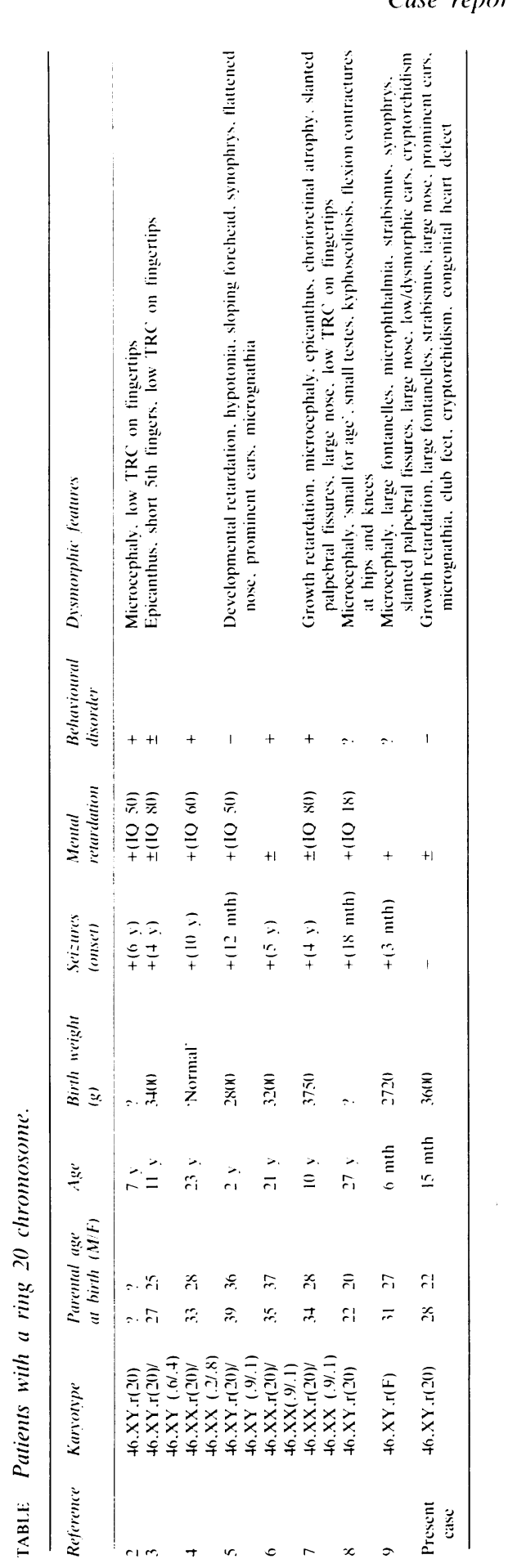


and cryptorchidism in males. Mental retardation was a consistent feature, though it was severe in only half of these patients. A characteristic finding was arrest of development at a certain age, with the appearance of behavioural abnormalities of various types (immature, impulsive, aggressive) in about $50 \%$ of cases. This clinical evolution was associated with occurrence of epileptic seizures, which were poorly controlled by treatment. The age of onset of seizures ranged from three months ${ }^{9}$ to 10 years. ${ }^{4}$

Our patient had neither seizures nor behavioural abnormalities which are considered distinguishing features of the $r(20)$ syndrome. It could well be that full expression of the syndrome has not yet become manifest in this young child because of the relatively late onset of encephalopathy and seizures. On the other hand, our patient presented with a complex congenital heart disease. This suggests that visceral malformations could represent the outer range of phenotypic expression in the narrow clinical spectrum of this rare chromosome imbalance.

\section{References}

' Borgaonkar DS. Lacassic YE. Stoll C. Usefulness of chromo- some catalog in delineating new syndromes. Birth Defects 1976:XII(5):87-95.

2 Atkins L. Miller WL. Salam M. A ring-20) chromosome. J Med Genet 1972:9:377-80.

3 Faed M. Morton HG, Robertson J. Ring F chromosome mosaicism $(46 . X Y .20 r / 46 . X Y)$ in an epileptic child without apparent haematological disease. J Med Genet 1972;9:470-3.

+ Uchida IA. Lin CC. Ring formation of chromosomes Nos 19 and 20. Cytogenetics 1972:11:208-15.

5 Stewart JM. Cavanagh N. Hughes DT. Ring 20 chromosome in a child with seizures. minor anomalies. and retardation. Arch Dis Child 1979:54:477-9.

" Herva R. Saarinen I, Leikkonen L. The r(20) syndrome. J Med Genet 1977:14:281-3.

7 Jalbert P. Jalbert H. Sele B. et al. Chromosome 20 en annau: un nouveau syndrome. Ann Genet (Paris) 1977:20:258-62.

$\checkmark$ Jacobs PA. Matsuura JS. Mayer M. Newlands IM. A cytogenetic survey of an institution for mentally retarded. I. Chromosome abnormalities. Clin Genet 1978:13:37-60.

" de Grouchy J. Plachot M. Sebaoun M. Bouchard R. Chromosome $\mathrm{F}$ en annau (46.XY.Fr) chez un garçon multimalformé. Ann Genet (Paris) 1972:15:121-6.

Correspondence and requests for reprints to Professor B Dallapiccola, Department of Public Health and Cell Biology, 2nd University of Rome, Via O Raimondo, I-00173 Rome, Italy. 